\title{
Correction to: Marked Intraindividual Cognitive Variability in a Sample of Healthy Graduate Students
}

\author{
Eliyas Jeffay ${ }^{1}$. Laurence M. Binder ${ }^{3} \cdot$ Konstantine K. Zakzanis $^{1,2}$
}

Published online: 6 August 2021

○) Springer Science+Business Media, LLC, part of Springer Nature 2021

\section{Correction to: Psychological Injury and Law https://doi.org/10.1007/s12207-021-09417-x}

After publication of this work, we noted that author affiliations were incorrectly attributed. The author affiliations have now been updated and modified accordingly. We are publishing this erratum to update the author information, which is as follows:

Eliyas Jeffay ${ }^{1}$, Laurence M. Binder ${ }^{3}$, Konstantine Zakzanis ${ }^{1,2}$

The original article has been corrected.

Publisher's Note Springer Nature remains neutral with regard to jurisdictional claims in published maps and institutional affiliations.

The original article can be found online at https://doi.org/10.1007/ s12207-021-09417-x.

Konstantine K. Zakzanis

konstantine.zakzanis@utoronto.ca

1 Department of Psychology, University of Toronto, Scarborough, 1265 Military Trail, Toronto, Ontario M1C 1A4, Canada

2 Graduate Department of Psychological Clinical Science, University of Toronto Scarborough, 1265 Military Trail,

Toronto, Ontario M1C 1A4, Canada

3 Independent Practice, Beaverton, OR, USA 